Revue d'histoire de l'Amérique française

REYUE D.HISTOIRE DE L'AMÉRIQUE FRANÇAISE

\title{
ARMSTRONG, Pat et Hugh ARMSTRONG, The Double Ghetto: Canadian Women and their Segregated Work. Toronto, McClelland and Stewart, 1978. 199 p. \$5.95.
}

\section{Jennifer Stoddart}

Volume 34, numéro 1, juin 1980

URI : https://id.erudit.org/iderudit/303840ar

DOI : https://doi.org/10.7202/303840ar

Aller au sommaire du numéro

Éditeur(s)

Institut d'histoire de l'Amérique française

ISSN

0035-2357 (imprimé)

1492-1383 (numérique)

Découvrir la revue

Citer ce compte rendu

Stoddart, J. (1980). Compte rendu de [ARMSTRONG, Pat et Hugh ARMSTRONG, The Double Ghetto: Canadian Women and their Segregated Work. Toronto, McClelland and Stewart, 1978. 199 p. \$5.95.] Revue d'histoire de l'Amérique française, 34(1), 99-100. https://doi.org/10.7202/303840ar d'utilisation que vous pouvez consulter en ligne.

https://apropos.erudit.org/fr/usagers/politique-dutilisation/ 


\section{COMPTES RENDUS}

ARMSTRONG, Pat et Hugh ARMSTRONG, The Double Ghetto: Canadian Women and their Segregated Work. Toronto, McClelland and Stewart, 1978. 199 p. \$5.95.

Paru il y a deux ans, l'ouvrage de Pat et Hugh Armstrong est déjà un classique en son genre. Voilà, enfin, une étude sur le travail féminin qui réussit à intégrer tous les aspects de l'activité économique des femmes, qu'elles soient salariées ou non. Pour la première fois, les Armstrong nous présentent une vue d'ensemble sur la condition économique des femmes, montrant comment leur double rôle de travailleuses salariées et de ménagères sans rémunération aucune se conjugue pour créer une situation de marginalisation et d'exploitation sur le marché du travail et au foyer.

Depuis dix ans, les analyses de la situation économique des femmes au Canada se font de plus en plus nombreuses. Mais, règle générale, ces études tombent dans une des deux catégories suivantes: ou bien, elles se résument à des compilations arides de salaires moyens et de taux de chômage; ou bien, elles proposent des explications intéressantes qui ne collent pas à la réalité économique quotidienne.

The Double Ghetto marie très bien les deux approches. C'est un livre-synthèse où les auteurs résument et expliquent la signification de la recherche faite sur le travail féminin, autant au Canada qu'à l'étranger, toujours selon leur thèse centrale. Celle-ci est que la ségrégation sexuelle du travail, tant à l'intérieur qu'à l'extérieur de la maison, se fait pour des raisons économiques qui ne se comprennent que par rapport à l'ensemble de l'organisation de la société.

Dans un premier chapitre sur le travail salarié, les auteurs font un résumé succinct de la position peu enviable des femmes sur le marché du travail. Quoique les données soient soigneusement présentées et les observations, perspicaces, rien ici ne distingue l'ouvrage d'autres de son genre. C'est dans le deuxième chapitre, qui porte sur le travail ménager, que l'on commence à apprécier l'approche originale. Intégrant tour à tour la théorie économique marxiste, les analyses féministes et les résultats de recherches sociologiques, les auteurs dressent un portrait de la ménagère canadienne dont le travail (bien qu'il soit rarement identifié par son nom) englobe la reproduction et l'éducation des enfants, les relations de la famille avec l'extérieur, l'harmonisation des tensions internes, les rapports sexuels et les tâches domestiques habituelles. Le véritable rôle de la ménagère apparaît quand il est décomposé selon les critères usuels : heures de travail, rémunération, formation, contenu de la tâche, conditions de travail, sélection, cadre juridique, etc.

RHAF, vol. $34, n^{\circ} 1$, juin 1980 
Les auteurs empruntent ensuite successivement les explications du déterminisme biologique et de l'idéalisme (c'est une affaire de mentalités) pour les disséquer et finalement les rejeter comme insatisfaisantes. Ils retiennent finalement l'hypothèse matérialiste, c'est-à-dire la recherche d'une explication dans les rapports de production et les structures qui les encadrent. Ce faisant, les auteurs nous offrent une application des plus facilement accessibles et des plus lucides de la théorie marxiste.

Le livre des Armstrong est doublement important. Au point de vue factuel, il nous propose un excellent résumé de l'état de la recherche au Canada sur les travailleuses / ménagères. Au point de vue des théories sur la condition féminine, il passe en revue systématiquement les justifications pseudo-scientifiques des préjugés courants sur les femmes, aussi bien que les approches qui préconisent de vagues changements dans notre échelle de valeurs. C'est donc une étude fort utile au point de vue pédagogique car elle expose les failles des explications idéalistes et biologiques. Le langage est clair, relativement dénué du jargon des spécialistes, et parfois très ironique.

Une seule réserve. En cherchant à faire ressortir nettement les différences entre l'approche matérialiste et les autres, les auteurs rejettent un peu trop rapidement différentes hypothèses sur la condition féminine, sans distinguer suffisamment entre les observations justes et les explications erronées. Toutefois, ceci n'enlève rien à la valeur d'ensemble de leur ouvrage qui demeurera pendant longtemps l'oeuvre fondamentale sur la condition économique des Canadiennes. 